\title{
Biological fractionations of lithium isotopes
}

\author{
NATHALIE VIGIER ${ }^{1}$, FANNY THIBON ${ }^{2}$, PACO \\ BUSTAMANTE ${ }^{3}$, LAURENT COUNILLON ${ }^{4}$, MARC

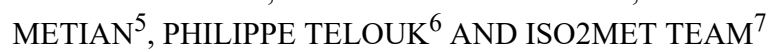

${ }^{1}$ LOV - CNRS - Sorbonne Université

${ }^{2}$ LOV- CNRS-Sorbonne Université

${ }^{3}$ LIENSs - CNRS-La Rochelle Université

${ }^{4}$ LP2M - Université Nice Cote d'Azur

${ }^{5}$ IAEA-REL

${ }^{6}$ ENS Lyon

${ }^{7}$ ANR ISO2MET: www.iso2met-project.fr/team

Presenting Author: nathalie.vigier@obs-vlfr.fr

$\mathrm{Li}$ isotopes have long been considered by geochemists as unaffected by biological processes, mainly because of the low $\mathrm{Li}$ concentrations in biologically-made materials. However, a large range of $d^{7} \mathrm{Li}$ values was reported in the literature for modern and coretop (recent) biogenic carbonates (e.g., Dellinger et al. 2018). Also, laboratory cultures confirmed variable $\mathrm{Li}$ isotope fractionations during foraminifera growth, depending on environmental parameters (Vigier et al. 2015; Roberts et al. 2018). Finally, a great range of $d^{7} \mathrm{Li}$ values (of $42 \%$ ) were displayed by various organs of a mammal model (Balter \& Vigier, 2014).

We will show how we recently reinforced these evidence by analysing numerous soft tissues from marine organisms, including calcifiers from different trophic levels (\#1). Most of them were collected in low Li marine environments and exhibit significant isotope fractionations (down to $-26 \%$ compared to SW). An experimental study performed with mussels indicates a strong effect of the aqueous $\mathrm{Li}$ level on their soft tissue $\mathrm{d}^{7} \mathrm{Li}$ value. Thus, variation of the environmental Li level appears to be a key parameter, through organism Li homeostasy and/or bioaccumulation, controling $\mathrm{Li}$ isotope signatures. Finally, experiments performed with cell lines expressing specific transporters demonstrate that the light ${ }^{6} \mathrm{Li}$ is transported much faster than ${ }^{7} \mathrm{Li}$ (by $\sim 15 \%$ ) through cell membranes.

All these observations highlight the necessity to consider the impact of environmental parameters, and in particular the $\mathrm{Li}$ concentrations, for interpreting past $\mathrm{d}^{7} \mathrm{Li}$ variations displayed by fossil shells. Providing precise $\mathrm{Li}$ isotope analyses of biological soft tissues (\#2) offers a complementary way to investigate the biological isotopy of trace metals and their importance in paleoceanography.

(\#1) Thibon et al., Goldschmidt 2021 (\#2) Weppe et al., Goldschmidt 2021 